\title{
The evolution of the European Respiratory Journal: volume 2
}

\author{
James D. Chalmers ${ }^{1}$ and Martin Kolb ${ }^{2}$ \\ Affiliations: 'Scottish Centre for Respiratory Research, University of Dundee, Ninewells Hospital and Medical \\ School, Dundee, UK. ${ }^{2}$ Firestone Institute for Respiratory Health St Joseph's Healthcare, Hamilton, ON,
} Canada.

Correspondence: James D. Chalmers, Division of Molecular and Clinical Medicine, University of Dundee, Dundee, DD1 9SY, UK. E-mail: jchalmersQdundee.ac.uk

@ERSpublications

The European Respiratory Journal review of 2018

http://ow.ly/FELu30ndxHN

Cite this article as: Chalmers JD, Kolb M. The evolution of the European Respiratory Journal: volume 2. Eur Respir J 2019; 53: 1802459 [https://doi.org/10.1183/13993003.02459-2018].

At the start of this, our second year in charge of the European Respiratory Journal, we want to take this opportunity to wish all of our readers, authors, reviewers and editors a very happy and successful 2019. It has been a busy and successful year at the journal with a record impact (more on this to come), exciting new series, excellent science and the addition of a few new faces at the journal. Here we present our review of 2018 and highlight some of the new features at the journal and what readers can expect from the ERJ in 2019.

\section{Highlights from 2018}

Randomised controlled trials (RCTs) remain the cornerstone of evidence-based medicine, and 2018 was a record year for the publication of high quality RCTs in the journal. The January issue alone included several primary RCT publications on topics as diverse as inhaler adherence, management of multimorbidity and self-management in COPD, two trials of inspiratory muscle training in COPD and the largest ever trials of inhaled antibiotics and physiotherapy management in bronchiectasis [1-9]. The journal encourages the submission of high quality randomised trials and to encourage the rapid dissemination of results we have introduced a fast track option. The ERJ will consider manuscripts that are high impact and clinically important (including randomised trials but also sometimes other manuscript types) for fast track review. As a result, some of the trials published this year were reviewed within 1 week and published within 1 month of submission $[5,7,10]$. Please contact the editors before submission to discuss if you think your manuscript may be suitable for fast track.

The ERJ is committed to covering the entire spectrum of respiratory medicine, to serve the interests of all European Respiratory Society (ERS) members. Emerging themes in 2018 include growing awareness of the hazards of air pollution [11-14], debate and new evidence on the risk of electronic cigarettes [15, 16] and increasing recognition of breathlessness as a clinical syndrome that should no longer be "Cinderella waiting to go to the ball" [17-21]. Basic and translational science also plays an important role in the journal, a point we emphasised again this year [22]. Publication and dissemination of ERS guidelines remain one of the major responsibilities of the journal [23]. The three most highly read papers during 2018 were, not unexpectedly, ERS guidelines with the guidelines for adult bronchiectasis, noninvasive ventilation, and hospital-acquired/ventilator associated pneumonia occupying places one, two and three respectively [24-26]. 
We have ended the year with a series of editorials highlighting the ERS Clinical Research Collaborations. These initiatives are the primary method by which the ERS supports clinical and translational research and each Clinical Research Collaboration represents the cutting edge of their individual field [27-31].

\section{Impact is not just about the impact factor}

The ERJ achieved its highest ever impact factor last year, reaching 12.24 and maintaining our position as the third-ranked journal in respiratory medicine. The high number of citations to articles of the ERJ is a credit to the ERJ authors, associate editors and reviewers who have helped us over the past years to select the very best papers for publication. The impact factor has important limitations, however, and we, as the chief editorial team, are keen that the health of the journal is evaluated by more than this one metric. It is widely accepted that the impact factor is relatively easy to manipulate, for example by only publishing articles in topics that are well cited, by publishing less original research and more reviews, or by aggressively cutting the number of papers published in the journal (since impact factor is the number of citations/number of articles published, cutting the denominator will nearly always result in an increase in the impact factor). The ERJ supports the recent updated guidance from the International Committee of Medical Journal Editors, which recommends using a range of metrics to evaluate journals and not just relying on the impact factor.

\section{What is changing at the ERJ?}

We have introduced a number of exciting new features to the journal over the past year and we take this opportunity to highlight a few. We hear that readers greatly value our review series and this is reflected in the download and readership metrics. Alongside our long running Back to Basics and State of the Art series we will continue to introduce new series, with more to follow in 2019. The first is focused on COPD and led by our section editor Don Sin, highlighting current controversies in COPD, including the role of inhaled corticosteroids, early COPD and imaging and biomarkers [32-34]. We are inviting submissions for a series on asthma to be published in late 2019. A successful new feature in the journal is ERJ Methods which was introduced in 2018 to give a guide to readers on the diverse and sometimes complex methodologies used in our speciality [35-37]. These are short mini-review papers intended to give non-experts the information required to understand and interpret the basics of cutting edge methods. We welcome unsolicited submissions and are happy to receive informal enquiries about potential topics for future ERJ Methods papers.

A relatively small change for 2019 is in the abstract format. The ERJ has historically had a 200 word unstructured abstract which is different to most of the other journals in the field which permit a structured (introduction/methods/results/conclusion) abstract of 250 words. From January 1, the ERJ will become aligned with the other journals in the field and expect a structured abstract of 250 words. Some manuscripts submitted before the end of 2018 will continue to be published with the previous abstract format. We hope the change will be beneficial for authors and also enhance the experience for readers.

\section{Peer review}

Peer review is the central pillar of the quality of the journal and we are grateful to all of the reviewers that have given their time voluntarily to the journal over the past year. We are always looking for new ways to engage our reviewers and involve them in the life of the journal. Many of the reviewers that have been most generous with their time have been invited to join the journal's editorial board over the years, and this year in Paris at the ERS International Congress we recognised five excellent reviewers with the 2018 ERJ peer review awards. These colleagues were Olivier Burgy, Myrofora Goutaki, Laurent Bertoletti, Peter Dorfmüller and Pierre-Regis Burgel. Will you be the winner in 2019?

\section{Welcoming the 6th World Symposium on Pulmonary Hypertension}

Thanks in no small part to the efforts of past-chief editor Marc Humbert, the ERJ has always had a strong tradition of publishing high quality and high impact research into pulmonary hypertension. This year, we are particularly proud that the organisers of the 6th World Symposium on Pulmonary Hypertension have chosen to publish their symposium proceedings in the ERJ. These manuscripts represent the cutting edge in the field across 13 papers and are highlighted in the editorial by Nazzareno Galiè and colleagues [38].

\section{Well done to our authors}

To our authors who published their manuscripts in the ERJ in 2018 we say congratulations. The ever-rising quality of submissions to the journal means that only exceptional studies are now published in the journal. The ERJ received around 2500 manuscript submissions in 2018 and can accept less than 10\% due to space limitations. The quality of manuscripts received by the journal increases year on year with the result that many excellent manuscripts have to be declined. Ensuring the very best papers are published 
includes a very careful peer review process. A typical manuscript submitted to the ERJ will be seen by the chief editors, a section editor with expertise in the specific topic and then an associate editor who may invite external peer reviewers. Potentially acceptable manuscripts will also undergo review by our statistical reviewers. If we said no to your paper in 2018, please forgive us! Peer review is not an exact science and your chief editors know from their own careers the disappointment of "the reject letter". We look forward to assessing and hopefully accepting your next paper. Nevertheless, it is pleasing that there are more options than ever before for our authors to publish their manuscripts. Our "sister" journals go from strength to strength, with ERJ Open Research now a high quality and high profile alternative for original research and other papers, while we are delighted to let readers know that the European Respiratory Review will receive its first impact factor in mid-2019, making it an attractive destination for review papers. Under the leadership of their new chief editors, Professor Alyn Morice and Professor Yochai Adir, we are sure these journals will further sharpen their profiles and facilitate seamless cooperation with the ERJ.

\section{Looking forward to 2019}

The ERJ is the flagship journal of the European Respiratory Society, the largest community of respiratory professionals in the world. As such, we have a responsibility to ensure that we publish the very best science and education and make the ERJ what its readers and authors want. We feel honoured to have to have the opportunity to review your work and guide the journal at this exciting time for our speciality. Bring on 2019!

Conflict of interest: J.D. Chalmers reports grants and personal fees from GlaxoSmithKline, Boehringer Ingelheim, Pfizer, Bayer Healthcare, Grifols and Insmed, grants from AstraZeneca, and personal fees from Napp and Aradigm Corporation, outside the submitted work. M. Kolb reports grants and personal fees from Roche, Boehringer Ingelheim, GSK, Gilead, Prometic and Alkermes, grants from Actelion, Respivert and Synairgen, and personal fees from AstraZeneca and Genoa, outside the submitted work.

\section{References}

1 Sulaiman I, Greene G, MacHale E, et al. A randomised clinical trial of feedback on inhaler adherence and technique in patients with severe uncontrolled asthma. Eur Respir J 2018; 51: 1701126.

2 Schultz K, Jelusic D, Wittmann M, et al. Inspiratory muscle training does not improve clinical outcomes in 3-week COPD rehabilitation: results from a randomised controlled trial. Eur Respir J 2018; 51: 1702000.

3 Beaumont M, Mialon P, Le Ber C, et al. Effects of inspiratory muscle training on dyspnoea in severe COPD patients during pulmonary rehabilitation: controlled randomised trial. Eur Respir J 2018; 51: 1701107.

4 Rose L, Istanboulian L, Carriere L, et al. Program of Integrated Care for Patients with Chronic Obstructive Pulmonary Disease and Multiple Comorbidities (PIC COPD ${ }^{+}$): a randomised controlled trial. Eur Respir J 2018; 51: 1701567.

5 De Soyza A, Aksamit T, Bandel T-J, et al. RESPIRE 1: a phase III placebo-controlled randomised trial of ciprofloxacin dry powder for inhalation in non-cystic fibrosis bronchiectasis. Eur Respir J 2018; 51: 1702052.

6 Chotirmall SH, Chalmers JD. RESPIRE: breathing new life into bronchiectasis. Eur Respir J 2018; 51: 1702444.

7 Aksamit T, De Soyza A, Bandel T-J, et al. RESPIRE 2: a phase III placebo-controlled randomised trial of ciprofloxacin dry powder for inhalation in non-cystic fibrosis bronchiectasis. Eur Respir J 2018; 51: 1702053.

8 Munoz G, de Gracia J, Buxo M, et al. Long-term benefits of airway clearance in bronchiectasis: a randomised placebo-controlled trial. Eur Respir J 2018; 51: 1701926.

9 Wong C, Sullivan C, Jayaram L. ELTGOL airway clearance in bronchiectasis: laying the bricks of evidence. Eur Respir J 2018; 51: 1702232.

10 Wells AU, Brown KK, Flaherty KR, et al. What's in a name? That which we call IPF, by any other name would act the same. Eur Respir J 2018; 51: 1800692.

11 Goeminne CP, Cox B, Finch S, et al. The impact of acute air pollution fluctuations on bronchiectasis pulmonary exacerbation: a case-crossover analysis. Eur Respir J 2018; 52: 1702557.

12 Brakema EA, Tabyshova A, Kasteleyn MJ, et al. High COPD prevalence at high altitude: does household air pollution play a role? Eur Respir J 2018; 52: 1801193.

13 Milanzi EB, Koppelman GH, Smit HA, et al. Air pollution exposure and lung function until age 16 years: the PIAMA birth cohort study. Eur Respir J 2018; 52: 1800218.

14 Havet A, Zerimech F, Sanchez M, et al. Outdoor air pollution, exhaled 8-isoprostane and current asthma in adults: the EGEA study. Eur Respir J 2018; 51: 1702036.

15 Bals R, Boyd J, Esposito S, et al. Electronic cigarettes: a task force report from the European Respiratory Society. Eur Respir J 2018; in press [https://doi.org/10.1183/13993003.01151-2018].

16 Ferkol TW, Farber HJ, La Grutta S, et al. Electronic cigarette use in youths: a position statement of the Forum of International Respiratory Societies. Eur Respir J 2018; 51: 1800278.

17 Johnson MJ, Fallon M. Chronic breathlessness: time for Cinderella to go to the ball! Eur Respir J 2018; 52: 1801452 .

18 Ahmadi Z, Sandberg J, Shannon-Honson A, et al. Is chronic breathlessness less recognised and treated compared with chronic pain? A case-based randomised controlled trial. Eur Respir J 2018; 52: 1800887.

19 Johnson MJ, Yorke J, Hansen-Flaschen J, et al. Chronic breathlessness: re-thinking the symptom. Eur Respir J 2018; 51: 1800340

20 Hutchinson A, Barclay-Klingle N, Galvin K, et al. Living with breathlessness: a systematic literature review and qualitative synthesis. Eur Respir J 2018; 51: 1701477.

21 Naeije R, Faoro V. The great breathlessness of cardiopulmonary diseases. Eur Respir J 2018; 51: 1702517.

22 Farre R, Hiemstra PS, Dinh-Xuan AT. Basic and translational research in the European Respiratory Journal. Eur Respir J 2018; 51: 1800377. 
23 Miravitlles M, Tonia T, Rigau D, et al. New era for European Respiratory Society clinical practice guidelines: joining efficiency and high methodological standards. Eur Respir J 2018; 51: 1800221.

24 Polverino E, Goeminne PC, McDonnell MJ, et al. European Respiratory Society guidelines for the management of adult bronchiectasis. Eur Respir J 2017; 50: 1700629.

25 Rochwerg B, Brochard L, Elliott MW, et al. Official ERS/ATS clinical practice guidelines: noninvasive ventilation for acute respiratory failure. Eur Respir J 2017; 50: 1602426.

26 Torres A, Niederman MS, Chastre J, et al. International ERS/ESICM/ESCMID/ALAT guidelines for the management of hospital-acquired pneumonia and ventilator-associated pneumonia. Eur Respir J 2017; 50: 1700582.

27 Brightling C, Genton C, Bill W, et al. ERS Clinical Research Collaborations: underpinning research excellence. Eur Respir J 2018; 52: 1801534.

28 Cunningham S, Gilbert C, Schwerk N. The European research collaboration for Children's Interstitial Lung Disease (ChILDEU) ERS Clinical Research Collaboration. Eur Respir J 2018; 52: 1801855.

29 Liu NM, van Aalderen W, Carlsen KCL, et al. Severe paediatric asthma collaborative in Europe (SPACE): protocol for a European registry. Breathe 2018; 14: 93-98.

30 Bonsignore MR, Hedner J. The European Sleep Apnoea Database (ESADA) ERS Clinical Research Collaboration: past, present and future. Eur Respir J 2018; 52: 1801666.

31 Sly PD, Hantos Z. The International Collaboration to Improve Respiratory Health in Children (INCIRCLE) ERS Clinical Research Collaboration. Eur Respir J 2018; 52: 1801867.

32 Leung JM, Sin DD. Inhaled corticosteroids in COPD: the final verdict is. Eur Respir J 2018; 52: 1801940.

33 Cazzola M, Rogliani P, Calzetta L, et al. Triple therapy versus single and dual long-acting bronchodilator therapy in COPD: a systematic review and meta-analysis. Eur Respir J 2018; 52: 1801586.

34 Soriano JB, Polverino F, Cosio BG. What is early COPD and why is it important? Eur Respir J 2018; 52 : 1801448.

35 Watson RL, de Koff EM, Bogaert D. Characterising the respiratory microbiome. Eur Respir J 2018; in press [https://doi.org/10.1183/13993003.01711-2018].

36 Dobler CC, Wilson ME, Murad MH. A pulmonologist's guide to understanding network meta-analysis. Eur Respir J 2018; 52: 1800525

37 Cabibbe AM, Walker TM, Niemann S, et al. Whole genome sequencing of Mycobacterium tuberculosis. Eur Respir J 2018; 52: 1801163.

38 Galie N, McLaughlin VV, Rubin LJ, et al. An overview of the 6th World Symposium on Pulmonary Hypertension. Eur Respir J 2019; 53: 1802148. 